\title{
Caminhos para o desenvolvimento turístico em Maricá, RJ
}

\author{
Pathways to tourism development in Maricá, RJ \\ Caminos para el desarrollo turístico en Maricá, RJ \\ Bruna Ranção Conti \\ Universidade Federal do Estado do Rio de Janeiro \\ (UNIRIO), Brasil \\ bruna.conti@unirio.br \\ Joice Lavandoski \\ Universidade Federal do Estado do Rio de Janeiro \\ (UNIRIO), Brasil \\ joice.lavandoski@unirio.br
}

\author{
DOI: https://doi.org/10.18472/cvt.19n1.2019.1529 \\ Redalyc: http://www.redalyc.org/articulo.oa? \\ $\mathrm{id}=115459473002$
}

Recepção: 12 Dezembro 2017

Aprovação: 22 Fevereiro 2019

\section{RESUMo:}

O turismo de base comunitária (TBC) vem se demonstrando como uma alternativa ao modelo convencional de desenvolvimento turístico que privilegia grandes investimentos em infraestrutura, iniciativa de grandes empresários de diferentes setores e ganhos econômicos que se sobrepõem às preocupações ambientais e sociais. Essa lógica vem sendo observada no município de Maricá, inserido no estado do Rio de Janeiro, com a futura implantação do complexo turístico-residencial Fazenda São Bento da Lagoa. $\mathrm{Na}$ contramão, está o interesse de pesquisadores e parte da gestão pública no fomento a uma lógica alternativa, o TBC. Este trabalho tem como objetivo analisar os dois modelos vigentes para o desenvolvimento do turismo em Maricá, isto é, o modelo convencional e, mais recentemente, o turismo de base comunitária. Para isso, são apresentadas as discussões teórico-conceituais sobre esses modelos. A metodologia desta pesquisa tem natureza exploratória e caráter qualitativo. Por meio de um Estudo de Caso, a análise Swot apresenta um diagnóstico para o turismo em Maricá, avaliando e contrapondo os dois modelos de desenvolvimento do turismo vigentes, a fim de identificar ameaças, fraquezas, oportunidades e fortalezas em ambos os projetos turísticos. Os resultados apontam para a necessidade da gestão pública entender esses modelos como complementares, privilegiando uma visão mais integrada dos interesses do coletivo e sua incorporação nas políticas públicas locais.

Palavras-chave: Turismo de Base Comunitária, Desenvolvimento, Complexo Turístico.

\section{Abstract:}

Community-based tourism (CBT) is proving itself as an alternative to the conventional model of tourism development that privileges large investments in infrastructure, initiative of large entrepreneurs from different sectors and economic gains that overlap environmental and social concerns. This logic has been observed in the city of Maricá, in the State of Rio de Janeiro, with the future implementation of the Fazenda São Bento da Lagoa tourist-residential complex. On the other hand, there is the interest of researchers and part of public management in fostering an alternative logic, the CBT. This research aims to analyze the two models for the Maricás tourism development in, that is, the conventional model and, more recently, the community-based tourism. For this, the theoretical-conceptual discussions about these models are presented. The methodology of this research has exploratory and qualitative natures. Through a Case Study, the Swot analysis presents a diagnosis for tourism in Maricá, evaluating and contrasting the two current models of tourism development, in order to identify threats, weaknesses, opportunities and strengths in both tourism projects. The results point to the need for public management to understands these models as complementary, favoring a more integrated view of collective interests and their incorporation into local public policies.

Keywords: Community-Based Tourism, Development, Tourist Complex.

\section{Resumen:}

El turismo de base comunitaria (TBC) se viene demostrando como una alternativa al modelo convencional de desarrollo turístico que privilegia grandes inversiones en infraestructura, iniciativa de grandes empresarios de diferentes sectores y lucros económicos que se superponen a las preocupaciones ambientales y sociales. Esta lógica viene siendo observada en el municipio de Maricá, en el Estado de Rio de Janeiro, con la futura implantación del complejo turístico-residencial Fazenda São Bento da Lagoa. En 
contramano, está el interés de investigadores y parte de la gestión pública en el fomento a una lógica alternativa, el TBC. Este trabajo tiene como objetivo analizar los dos modelos vigentes para el desarrollo del turismo en Maricá, es decir, el modelo convencional y, más recientemente, el turismo de base comunitaria. Para ello, se presentan las discusiones teórico-conceptuales sobre estos modelos. La metodología de esta investigación tiene naturaleza exploratoria y carácter cualitativo. El análisis Swot presenta un diagnóstico para el turismo en Maricá, evaluando y contraponiendo los dos modelos de desarrollo del turismo vigentes, a fin de identificar amenazas, debilidades, oportunidades y fortalezas en ambos proyectos turísticos. Los resultados apuntan a la necesidad de la gestión pública entender estos modelos como complementarios, privilegiando una visión más integrada de los intereses del colectivo y su incorporación en las políticas públicas locales.

Palabras clave: Turismo de Base Comunitaria, Desarrollo, Complejo Turístico.

Um dos mais propagados benefícios do turismo é o seu potencial de promover o crescimento econômico de um local. É justamente por meio desse efeito do turismo na economia que gestores públicos e privados de cidades, sejam elas de grande ou de pequeno porte, urbanas ou rurais, se veem atraídos pelo turismo. Dessa forma, o turismo passa a ser uma atividade que, muitas vezes, serve apenas ao crescimento econômico e não, necessariamente, ao desenvolvimento local (GABRIELLI, 2017).

Estudos alertam para que o planejamento do turismo contemple o desenvolvimento nas suas múltiplas esferas, ou seja, econômica, cultural e social, sendo um processo participativo e que respeite as especificidades locais (CORIOLANO, 2012; HALL, 2001; YÁZIGI, 2009). O planejamento com o objetivo de desenvolvimento deve ser muito bem avaliado por todos os envolvidos direta e indiretamente com a atividade turística, no sentido de refletirem sobre qual "desenvolvimento" se quer alcançar. Segundo Hall (2001, p. 55), um planejamento participativo pode assegurar um "desenvolvimento na comunidade e não da comunidade".

Silva e Miranda (2013) afirmam que tão importante quanto os benefícios econômicos, é a capacidade que o turismo tem de promover o desenvolvimento local, a partir da valorização da cultura, da conservação do meio natural e da promoção do bem-estar social. É dessa forma que o turismo irá gerar um retorno positivo para a população local. E, nesse sentido, a administração pública tem grandes responsabilidades, pois é essa a instituição que deve planejar o turismo na cidade, priorizando as necessidades e os desejos dessa população, além de garantir que o desenvolvimento do turismo não seja um elemento de exclusão de parte dela.

Problemas de governança pública local, ausência de políticas públicas de turismo e a falta de participação da população nas tomadas de decisões são algumas das barreiras para as estratégias de desenvolvimento do turismo. Para Gabrielli (2017), é eminente pensar em políticas públicas de âmbito nacional, estadual e municipal com o intuito de valorizar as ações voltadas para uma prática turística mais responsável, ou seja, diminuindo os seus impactos negativos e possibilitando que formas tradicionais e alternativas ${ }^{[1]}$ de turismo coexistam harmonicamente, de acordo com a realidade de cada local.

Entre essas formas alternativas, o turismo de base comunitária (TBC) vem sendo apresentado como um contraponto ao modelo convencional de desenvolvimento turístico, que privilegia grandes investimentos em infraestrutura, iniciativa de grandes empresários de diferentes setores e ganhos econômicos que se sobrepõem às preocupações ambientais e sociais. Essa forma de pensar o desenvolvimento do turismo o considera como fenômeno social que pode desencadear impactos positivos e negativos no que diz respeito à valorização da cultura local, ao empoderamento e à participação dos moradores locais no planejamento e na gestão de seu próprio desenvolvimento e, ainda, no que diz respeito à coesão social. Assim, para o TBC, o turismo deixa de ser mera atividade econômica para assimilar os princípios da cooperação na gestão dos empreendimentos da própria localidade, as territorialidades locais como elementos fundamentais para a criação de valor turístico e o protagonismo da população na busca por um desenvolvimento local.

A partir do exposto, duas lógicas de desenvolvimento do turismo vêm sendo observadas no município de Maricá, inserido na região metropolitana do estado do Rio de Janeiro. O modelo convencional, pautado na lógica de mercado, está presente no projeto do complexo turístico-residencial Fazenda São Bento da Lagoa, 
previsto para ser implementado no município. Em oposição, está o interesse de pesquisadores e parte da gestão pública no fomento a uma lógica alternativa, o TBC.

Nesse sentido, este trabalho tem como objetivo analisar os dois modelos vigentes para o desenvolvimento do turismo em Maricá, o modelo convencional e o turismo de base comunitária. Como objetivos específicos destacam-se: a) discutir os diferentes caminhos possíveis para um desenvolvimento turístico municipal e suas implicações locais; b) entender a realidade do município de Maricá; c) diagnosticar os projetos de turismo em curso no município e suas viabilidades.

Para tanto, a metodologia do trabalho envolveu a discussão dos modelos de desenvolvimento do turismo; a revisão dos documentos do projeto complexo turístico-residencial Fazenda São Bento da Lagoa e do Projeto de Extensão "Economia Solidária e Turismo de Base Comunitária em Maricá/RJ", atualmente vigentes em Maricá; e a realização de um diagnóstico local, buscando comparar a lógica de desenvolvimento dos projetos supracitados, por meio da análise Swot. Essa construção metodológica considerou a triangulação de dados, técnicas e informações sobre o contexto e objeto analisado.

A realização deste trabalho se justifica pela oportunidade de subsidiar o planejamento do turismo em Maricá de forma integrada, justa, participativa, levando em consideração os interesses de todos os envolvidos no processo. É também um meio de oferecer novos olhares e alternativas econômicas para o município, que conjugam a valorização dos modos de vida locais e do saber-fazer, impactando positivamente na autoestima e bem-estar dos residentes.

Este trabalho está organizado em cinco seções, além desta introdução. As duas primeiras seções apresentam uma discussão sobre os modelos de desenvolvimento do turismo, sobre o papel do Estado na promoção desses modelos e seus impactos no cotidiano da sociedade, destacando-se os complexos turísticos de grande porte e o TBC. A terceira seção detalha a metodologia utilizada neste trabalho. Na sequência, são apresentadas as características geográficas e turísticas do município e desenvolvido um diagnóstico do turismo em Maricá, contrapondo os dois modelos de desenvolvimento turístico vigentes no município. Por fim, são apresentadas as considerações finais desta análise, propondo recomendações no âmbito do planejamento turístico para a gestão pública e privada de Maricá. Tais recomendações são, justamente, a contribuição prática deste estudo.

No âmbito teórico, este trabalho oferece uma discussão integrada de dois modelos de desenvolvimento do turismo e sua importância para um município de médio porte que possui sua economia baseada na exploração do petróleo. E, nesse quesito, a análise Swot apresenta-se como uma ferramenta interessante para a identificação, avaliação e, também, para análises comparativas de cenários concretos e de caráter atual.

\section{DESENVOLVIMENTO DO TURISMO: IMPLICAÇÕES DO MODELO CONVENCIONAL}

As duas décadas finais do século $\mathrm{XX}$ foram marcadas por várias mudanças nas trajetórias políticas, econômicas e ideológicas, em âmbito internacional e nacional. A agenda neoliberal emergiu desconstruindo e substituindo as agendas desenvolvimentistas, que foram executadas dos anos 1930 aos anos 1970, nos países desenvolvidos e em alguns países em desenvolvimento. Essa agenda se baseou na defesa da democracia liberal, no campo político; nas reformas orientadas para o mercado e nas políticas de estabilização, no campo econômico; e no predomínio da teoria econômica ortodoxa, da globalização e do questionamento à intervenção estatal, no campo ideológico. Foram muitas as mudanças que essa agenda implicou para as políticas de desenvolvimento nacionais, com destaque para a redução do papel do Estado na organização da vida econômica e social.

Segundo essa ideologia, os mercados, os atores econômicos e a teoria econômica ortodoxa tomariam a dianteira e se encarregariam de promover o desenvolvimento. O Estado deveria então se adaptar a tal contexto, implementando as melhores práticas sugeridas por esses atores, que se concentravam nas políticas pró-mercado e em uma gestão pública tecnocrática. Assim, a partir da redução das barreiras físicas e 
financeiras entre os países, do aumento do fluxo de produtos, serviços, capital e conhecimento, a eficiência dos mercados aumentaria, bastando que os governos promovessem a estrutura necessária ao livre funcionamento daqueles (ANTUNES; CONTI, 2012).

No âmbito do turismo nacional, essa agenda é facilmente percebida nas políticas públicas implementadas a partir de 1970, voltadas ao fomento da "indústria do turismo" e à provisão de recursos para o financiamento de empreendimentos tidos à época como essenciais ao crescimento do setor, com destaque para os complexos turísticos de grande porte e hotéis de luxo de redes internacionais. Cada vez mais o turismo passou a ser visto como fonte de geração de emprego e renda, um meio para a geração de divisas e estratégia de desenvolvimento econômico, inserido em uma lógica de adequação dos produtos brasileiros às necessidades do mercado externo e de favorecimento da iniciativa privada.

As consequências gerais que podem ser observadas com a adoção da agenda neoliberal são várias, mas o balanço que se faz dos seus resultados é predominantemente negativo (STIGLITZ, 2002). De fato, a globalização, acompanhada da diminuição das barreiras ao comércio, aos capitais e ao conhecimento, proporcionou a entrada de vários países na lógica econômica moderna, com a industrialização de suas economias e a proliferação das tecnologias avançadas. Além disso, as multinacionais ganharam poder e aumentaram seus lucros consideravelmente, pois puderam aproveitar as economias proporcionadas pela abertura dos mercados e pela flexibilização das regulamentações nacionais.

Entretanto, o crescimento econômico nos países que aplicaram as recomendações foi, em geral, bem mais modesto do que o prometido. A desregulamentação dos mercados acabou promovendo a instabilidade econômica mediante crises provocadas pelos abusos de integrantes do mercado e pela especulação excessiva, por exemplo. Além dos problemas econômicos, também se constatou o aumento das desigualdades sociais nos países que seguiram as práticas recomendadas pela agenda (STIGLITZ, 2002). Foi também marcante, nas últimas décadas, o agravamento dos problemas ambientais em nível mundial, dado que muitas vezes as iniciativas de proteção da natureza foram sobrepujadas pelos interesses econômicos.

No contexto do turismo, os impactos negativos do acirramento de um turismo de massa são cada vez mais evidentes. A propagação desenfreada do turismo, sobretudo o turismo de massa, pode torná-lo mais produtivo economicamente, mas, também, pode gerar graves impactos negativos para o ambiente onde ele se perpetua e para a população local. Há uma corrente de pesquisadores que se preocupam com essas manifestações predatórias e autofágicas do turismo (HALL, 2001; KRIPEENDORF, 2003; YÁZIGI, 2009), e que apontam para diferentes problemas relacionados ao uso e à ocupação do espaço para fins turísticos sem o devido controle do Estado, entre eles: sobrecarregar a infraestrutura básica; deteriorar os espaços públicos; comprometer reservas ambientais por meio de uma ocupação irregular por condomínios e hotéis; gerar especulação imobiliária e supervalorização de terras; provocar a emigração da população local e, até mesmo, a criação de zonas periféricas para acomodar a população de baixa renda.

Diante do apresentado, o cenário atual torna possível e necessária a consolidação de uma nova agenda desenvolvimentista. Não são poucas as propostas para essa nova agenda. Para citar algumas, destacam-se as propostas do ecodesenvolvimento (SACHS, 1980), do desenvolvimento sustentável (CMMAD, 1991), do desenvolvimento como liberdade (SEN, 2000), entre outras ${ }^{[2]}$. No entanto, embora haja uma abundância de contribuições sobre os princípios que devem sustentar esse novo modelo, a sua implementação ainda é pouco discutida na esfera acadêmica e pouco colocada em prática na gestão pública em nível local. Nesse sentido, busca-se aqui apresentar uma pequena contribuição à análise dos desafios da implementação de uma nova lógica de desenvolvimento aplicada ao turismo, o turismo de base comunitária. 


\section{O TURISMO DE BASE COMUNITÁRIA COMO MODELO ALTERNATIVO DE DESENVOLVIMENTO TURÍSTICO}

O turismo de base comunitária é um modelo de desenvolvimento e organização do turismo que propõe o protagonismo da população local na gestão dessa atividade econômica, por meio de mecanismos de autogestão, da manutenção da propriedade do território e da democratização de oportunidades e benefícios. Mas é também um movimento que entende o turismo como fenômeno social, buscando ir além dos resultados econômicos e incorporar a valorização dos saberes tradicionais e da cultura local, o fortalecimento das relações sociais, a melhoria da qualidade de vida dos agentes envolvidos no processo e a conservação dos recursos naturais.

Esse modelo alternativo de desenvolvimento do turismo surge em um contexto mais amplo de crítica aos efeitos do capitalismo, tanto no questionamento à sua capacidade de promover a redução das desigualdades sociais e a melhoria do bem-estar da população em geral, quanto nas constatações sobre os impactos ambientais gerados pela expansão desenfreada das atividades econômicas. Essas constatações dão origem a uma série de novas propostas de desenvolvimento em diversas áreas. E, no campo do turismo, uma discussão que passou a ganhar relevância foi a do turismo de base comunitária, como proposta de redução dos impactos negativos causados pelo modelo tradicional de desenvolvimento do turismo e, ao mesmo tempo, de promoção do protagonismo da população local no planejamento e gestão do fenômeno (BURGOS; MERTENS, 2015; BURSZTYN; BARTHOLO, 2012; FABRINO; NASCIMENTO; COSTA, 2016; GÓMEZ et al., 2015; MENDONÇA et al., 2016; MIELKE; PEGAS, 2013).

De acordo com Okazaki (2008), os primeiros pesquisadores a abordar o tema em questão defendiam a ideia de que a participação dos atores locais na promoção do turismo deveria ser o ponto central de atuação de projetos nesse sentido, uma vez que: (a) questões locais influenciam diretamente a experiência turística; (b) a imagem do turismo está baseada nos bens comunitários, incluindo não só as pessoas mas, também, o ambiente natural, a infraestrutura e os aspectos culturais locais; (c) a sustentabilidade do turismo em longo prazo depende da sua capacidade em promover o desenvolvimento socioeconômico local.

Nesse sentido, promover um turismo de base comunitária seria não só uma forma de distribuir de maneira mais equitativa os resultados econômicos das atividades turísticas, mas também de promover a autogestão, na medida em que o poder sobre os meios de produção e o território é atribuído à própria população. Esse viés de organização popular faz do TBC um fenômeno que mescla iniciativas de cunho econômico com características de um movimento social.

No entanto, para Irving (2009), apenas recentemente as produções nessa área do conhecimento ganharam força, o que coincide com o momento histórico em que o turismo, entendido apenas como mera atividade econômica, passa a sofrer uma série de críticas relacionadas aos impactos sociais, culturais e ambientais que ocasionou em diversos destinos mundiais e brasileiros. Assim, as experiências de TBC começaram a ser identificadas e analisadas apenas a partir da década de 1990 (OKAZAKI, 2008), e, no Brasil, o Encontro Nacional de Turismo de Base Local, realizado pela primeira vez em 1997, foi o primeiro evento nacional a se dedicar ao tema.

Vale ressaltar que a década de 1990 foi também um momento de fortalecimento da democracia no Brasil e das reivindicações pela ampliação da participação da sociedade civil nas tomadas de decisão. Nesse caminho, algumas iniciativas brasileiras de TBC começaram a esboçar a construção de um movimento social organizado no início dos anos 2000, que culminou na criação da Rede Brasileira de Turismo Solidário e Comunitário (Turisol), em 2003. Entretanto, nos seus primeiros anos, essa rede se restringiu ao diálogo entre as organizações participantes, não realizando projetos comuns nem atuando como um movimento social capaz de estabelecer uma agenda de políticas públicas para o TBC no País (CONTI et al., 2018).

Foi apenas em 2007, com o apoio da ONG Ashoka Empreendedores Sociais, que representantes de alguns dos projetos participantes da Rede Turisol realizaram um encontro para promover a consolidação da rede 
(TURISOL, 2019). No mesmo ano, o TBC passa a ser objeto de atenção do Ministério do Turismo, o que resultou no lançamento do Edital MTur 001/2008, o primeiro do ministério voltado ao tema, com o objeto de selecionar projetos de fomento a iniciativas de TBC e que promovam a inserção destas na economia de mercado, com base nos princípios de economia solidária.

Apesar desses esforços iniciais, tanto a incipiente política pública para o TBC quanto a própria Rede Turisol sofreram problemas de continuidade nos anos seguintes. Nem todos os projetos aprovados no edital de 2008 foram contemplados com recursos e, dos que foram, alguns não conseguiram cumprir os requisitos burocráticos para execução do projeto (SILVA et al., 2016). Além disso, após a finalização dos recursos oriundos do edital, a Rede Turisol novamente se desarticulou, voltando a se reunir apenas em 2014, em uma reunião durante o XIII ENTBL e por meio da realização do II Encontro da Rede Brasileira de Turismo Solidário e Comunitário, em 2015. De acordo com Mielke (2011), o caráter pontual do edital e a descontinuidade da política pública brasileira de TBC acabaram por criar mais barreiras do que fortalecer, de fato, a Rede.

Apesar disso, o tema do TBC vem ganhando força no âmbito de outras instâncias e níveis governamentais, como, por exemplo, a estratégia atual do Instituto Chico Mendes de Conservação da Biodiversidade (ICMBio) em garantir o desenvolvimento econômico e social de comunidades inseridas ou localizadas no entorno de unidades de conservação por meio do apoio a iniciativas de TBC (MMA, 2018). Em diversos municípios brasileiros se constata também o interesse crescente nessa estratégia de promoção do turismo, como é o caso de Maricá, no estado do Rio de Janeiro.

\section{METODOLOGIA}

Esta é uma pesquisa de natureza exploratória, de caráter qualitativo e que adota, como estratégia metodológica, um estudo de caso aplicado ao município de Maricá. O estudo de caso pode ser definido como um procedimento metodológico com pretensóes holísticas, na medida em que procura compreender e interpretar diversas dimensões de uma situação ou fenômeno específico. Pressupõe, portanto, a investigação aprofundada de um fenômeno complexo, com a finalidade de descrever e analisar acontecimentos, agentes, situações, utilizando diferentes perspectivas metodológicas oriundas de abordagens qualitativas ou quantitativas. Além disso, seu caráter aplicado permite produzir diagnósticos e prognósticos que orientam processos de tomada de decisão (VEAL, 2011; YIN, 2001).

O estudo de caso utilizado neste trabalho é de caso único e do tipo analítico, aplicado para a avaliação de modelos de desenvolvimento do turismo. Concentra-se a análise na problematização de dois possíveis caminhos para o desenvolvimento do turismo em Maricá. Assim, as questões norteadoras desta pesquisa são: Como a atividade turística pode contribuir para a valorização das iniciativas locais em Maricá? Como conciliar os diferentes interesses envolvidos no planejamento e na gestão do turismo no local estudado?

Para a construção deste trabalho foi realizada uma revisão bibliográfica sobre os temas desenvolvimento turístico, turismo de base comunitária e sobre o processo de implantação do complexo turístico-residencial Fazenda São Bento da Lagoa. Uma pesquisa documental foi realizada nos projetos de turismo no município, além do levantamento de dados secundários disponíveis em páginas da internet, entre elas da Prefeitura Municipal de Maricá, de mídias/materiais jornalísticos e da empresa IDB Brasil, responsável pela instalação do complexo.

Outra técnica de pesquisa utilizada foi a observação direta, durante os meses de fevereiro a dezembro de 2017, por meio do Projeto de Extensão titulado "Economia Solidária e Turismo de Base Comunitária em Maricá/RJ”, realizado pelo Departamento de Turismo e Patrimônio da Universidade Federal do Estado do Rio de Janeiro (Unirio), que permitiu identificar e compreender a realidade local, assim como um aprofundamento das questões conceituais aplicadas para o contexto (Maricá) e objeto analisado (projetos turísticos). As observações foram realizadas durante as reuniões técnicas de trabalho e os encontros de 
formação com integrantes da gestão pública, privada e com a comunidade local, bem como no decorrer das visitas técnicas aos empreendimentos com potencial para fomentar o turismo de base comunitária.

Por fim, a análise Swot foi utilizada com o objetivo de realizar uma análise de cenários, avaliando e contrapondo os dois modelos de desenvolvimento do turismo vigentes em Maricá, a fim de identificar ameaças, fraquezas, oportunidades e fortalezas em ambos os projetos turísticos.

\section{MARICÁ COMO ESTUDO DE CASO}

Maricá é um município de porte médio localizado na Região Metropolitana do Rio de Janeiro, no estado do Rio de Janeiro, distando aproximadamente $60 \mathrm{~km}$ da capital e contando com cerca de 150 mil habitantes (IBGE). O território municipal é dividido em quatro distritos: Centro, Ponta Negra, Inoã e Itaipuaçu, e seu acesso pode ser feito tanto pela RJ-106 (Rodovia Amaral Peixoto), que liga o município às cidades de Niterói, São Gonçalo e Saquarema, quanto pela RJ-114, que faz a conexão com o município de Itaboraí e com as rodovias RJ-104 e BR-101.

As características de Maricá vêm se transformando consideravelmente nos últimos anos, principalmente após a duplicação da Rodovia Amaral Peixoto (RJ-106) em 2002, quando muitos veranistas fixaram residência no município e novos investidores foram atraídos para o local, estimulando a especulação imobiliária e o crescimento populacional. Apesar de já ter sido um município que baseava sua economia essencialmente na agricultura e na pesca, a principal atividade econômica atual de Maricá é a exploração do petróleo, principalmente após a consolidação de dois elementos: (a) a exploração de petróleo na camada do Pré-Sal e, (b) o Complexo Petroquímico do Rio de Janeiro (Comperj). Nesse contexto, a exploração do campo de Lula, pela Petrobras, é a principal atividade que garante receitas aos cofres da prefeitura, sendo este o município do estado do Rio de Janeiro que mais recebeu verbas advindas de royalties do petróleo em 2017 [3].

O município pertence à região turística da Costa do Sol, juntamente com Araruama, Búzios, Arraial do Cabo, Cabo Frio, Caperebus, Casimiro de Abreu, Iguaba Grande, Macaé, Quissamã, Rio das Ostras, São Pedro da Aldeia e Saquarema, sendo esta uma das principais regiões turísticas do estado. Os principais atrativos da região estão ligados ao segmento sol e praia. Destaca-se ainda, em Maricá, a existência de um grande complexo lagunar, um dos maiores do estado, que contempla as lagoas de Maricá, Barra de Maricá, do Padre, Guaripina e Jaconé, além dos canais de Ponta Negra e de Itaipuaçu, que ligam as lagoas ao mar. É também rodeado por maciços costeiros, praias oceânicas, pelo Parque Estadual da Serra da Tiririca e pela Área de Proteção Ambiental Estadual de Maricá. Além disso, o município possui diversas unidades de conservação municipais.

Apesar de Maricá não possuir sua economia baseada no turismo, o poder público municipal reconhece as potencialidades locais e já vislumbra a possibilidade de o turismo se tornar uma das principais atividades econômicas locais, como discutido na seção a seguir.

\subsection{Discussão dos modelos}

Atualmente é possível perceber a implantação de dois modelos de desenvolvimento do turismo em Maricá. $\mathrm{O}$ modelo vinculado à ideia mais tradicional de incorporação de grandes estruturas turísticas, voltadas à atração de um público de alta renda, e financiadas, em parte, pela iniciativa privada estrangeira, detentora, inicialmente, da expertise necessária ao crescimento do turismo - entendido como setor econômico capaz de dinamizar a economia local, gerar emprego, renda e arrecadação de impostos pelo município. Por outro lado, teve início, mais recentemente, a implantação de outro modelo, mais voltado ao fortalecimento dos empreendimentos locais já existentes, notadamente aqueles que se organizam por meio de uma base coletiva 
ou associativa e que estão diretamente vinculados às características locais, qual seja, o turismo de base comunitária. Este último modelo começa a ser encampado principalmente sob o viés da economia solidária.

O primeiro modelo de desenvolvimento do turismo em Maricá é representado pelo complexo turísticoresidencial Fazenda São Bento da Lagoa, que vem sendo planejado desde 2007 pelo grupo empresarial Iniciativas e Desenvolvimento Imobiliário (IDB Brasil), de capital espanhol. Esse empreendimento será implantado em parte da Área de Proteção Ambiental de Maricá ${ }^{[4]}$ (APA de Maricá), e será constituído por moradias de luxo residenciais, hotéis, marina privada, grandes zonas desportivas (incluindo campo de golfe e centro hípico), parque empresarial, clubes, shopping center, escolas e hospitais (MATIAS; CORREA, 2010). O complexo irá compreender a área conhecida como restinga ${ }^{[5]}$ de Maricá, que engloba a antiga Fazenda São Bento da Lagoa, além de um conjunto de pescadores artesanais e uma área indígena, que serão diretamente impactados pelo empreendimento.

Com relação aos atributos ambientais da restinga, esta se caracteriza por apresentar uma grande diversidade biológica e um ecossistema frágil, além de sua importância do ponto de vista paisagístico, contando com uma grande variedade de orquídeas, bromélias e epífitas. Dessa forma, a própria criação da APA de Maricá teve como justificativa a conservação desse ambiente e o controle do processo de urbanização no local, tendo em vista que regiões de restinga possuem grande valorização imobiliária, dada à proximidade com o mar, as belezas naturais e seu potencial turístico (PEREIRA; MELLO, 2011). Com relação às comunidades tradicionais que habitam a área, destacam-se os pescadores artesanais de Zacarias e a aldeia indígena Mata Verde Bonita.

A comunidade de Zacarias situa-se às margens da Lagoa de Maricá há mais de dois séculos, tendo sido inserida nos limites da APA de Maricá. Segundo relatos dos próprios moradores, habitam na comunidade cerca de 60 famílias que vivem da pesca artesanal, sendo uma população com mais de 300 pessoas (LOUREIRO; MATIAS; FREIRE, 2010). Os moradores não possuem título de propriedade da terra o que, por diversas vezes, desencadeou conflitos com a equipe de gestão da APA e com a própria prefeitura. Tais conflitos estão novamente em voga desde o início das conversas sobre a implantação do complexo turístico-residencial Fazenda São Bento da Lagoa, principalmente porque a primeira tentativa do grupo IDB Brasil foi a de remover os pescadores da sua área original, conforme relatado pelo presidente da Associação Comunitária de Cultura e Lazer dos Pescadores de Zacarias (ACCLAPEZ) [6].

A aldeia indígena Mata Verde Bonita se instalou em Maricá em 2013, na área da restinga, ocupando uma extensão territorial de três hectares doados pela prefeitura. No entanto, a área doada pertence ao grupo IDB Brasil, o que também levou à conformação de conflitos com essa comunidade. Atualmente, de acordo com o cacique da aldeia e representantes da prefeitura ${ }^{[7]}$, o grupo IDB passou a apoiar a permanência dos indígenas no local por acreditar que estes poderão desempenhar um papel de atração dos turistas. A princípio, essa ideia vem sendo corroborada pelos indígenas, que visualizam a possibilidade de ganhos econômicos, principalmente com o comércio de artesanato, e de divulgação e valorização de sua cultura.

O grupo empresarial que controla a IDB Brasil já construiu e vem operando outros empreendimentos turístico-residenciais, similares ao pretendido, estando dois deles localizados na Espanha e um na Índia. De acordo com o Relatório de Impacto Ambiental do complexo turístico-residencial Fazenda São Bento da Lagoa ${ }^{[8]}$, o empreendimento foi planejado com base nos princípios de sustentabilidade ambiental, visando criar infraestrutura urbana completa em habitação, turismo, vivência comunitária e preservação ambiental; além de infraestrutura com arruamentos pavimentados; rede de águas pluviais; rede de esgotamento sanitário; abastecimento de água; sistema terciário de tratamento de esgotos sanitários; e iluminação pública. $\mathrm{O}$ relatório evidencia ainda os compromissos de criação de uma Reserva Particular do Patrimônio Natural (RPPN), com extensão de 437 hectares, um Centro de Referência Ambiental para dar suporte às pesquisas científicas, à produção de mudas de espécies da flora local e ao uso público da RPPN, e o compromisso de manutenção da comunidade de Zacarias e de sua regularização fundiária (transferência da titularidade e dos direitos de uso e ocupação dos respectivos lotes pelos atuais moradores). 
Estudos científicos já realizados sobre os possíveis impactos do empreendimento e sobre a percepção dos moradores evidenciam grande preocupação dos pontos de vista ambiental e social (LOUREIRO; MATIAS; FREIRE, 2010; PEREIRA; MELLO, 2011; SOUZA, 2015). Nesse sentido, a Comissão de Direitos Humanos da Alerj elaborou um relatório sobre o caso, destacando que há um estado de violação da legislação ambiental e urbanística e de violação de direitos humanos, no caso da comunidade tradicional de Zacarias. De acordo com o relatório, desde que o projeto foi anunciado, os pescadores relatam que têm sido vítimas de ameaças, vigilância e intimidações que geram fragmentação e divisões internas. $\mathrm{O}$ documento da Alerj conclui ainda que a concretização do megaempreendimento "esvazia de sentido a criação da APA Maricá, pois, além de acarretar perda de biodiversidade, transfere à iniciativa privada parte da área de proteção, que deveria ser patrimônio coletivo" [9].

O segundo modelo de desenvolvimento do turismo em Maricá é representado por iniciativas de economia solidária promovidas pela Prefeitura Municipal, levando em consideração os interesses de parte da comunidade local. As iniciativas compreendem o fortalecimento do cooperativismo, a ampliação do benefício da moeda social "Mumbuca [10]", a criação do Banco Comunitário Popular de Maricá e o Projeto "Economia Solidária e Turismo de Base Comunitária em Maricá/RJ”. Em relação ao projeto, este vem sendo desenvolvido por meio de parcerias do Departamento de Turismo e Patrimônio da Universidade Federal do Estado do Rio de Janeiro (Pró-Reitoria de Extensão e Cultura/Unirio), com a gestão pública de Maricá, especificamente com as Secretarias de Economia Solidária e de Turismo; e com a Superintendência Regional do Trabalho e Emprego do Rio de Janeiro/Ministério do Trabalho (SRTE-RJ). O projeto tem como objetivo embasar o desenvolvimento do turismo de base comunitária em Maricá, envolvendo articulação entre as secretarias, formação em Ecosol e TBC, realização de inventário do turismo de base comunitária e elaboração conjunta de um roteiro.

Ao longo da vigência do projeto (fevereiro/2017 a novembro/2018), foram realizadas reuniões de alinhamento com as secretarias municipais (Economia Solidária; Turismo; Educação; Agricultura, Pecuária e Pesca; Planejamento, Orçamento e Gestão e Companhia de Desenvolvimento de Maricá; além da Seção de Economia Solidária da SRTE- RJ). Foram promovidos também cinco encontros de formação em Ecosol e TBC, um dos encontros com representantes da Prefeitura $(n=21)$, e os outros quatro com atores locais (principalmente aqueles inseridos em empreendimentos, formais ou não, com potencial para fomentar o TBC) $(n=26)$, totalizando 57 participantes.

A equipe do projeto realizou um levantamento dos empreendimentos e atrativos potenciais para o TBC no município, por meio da metodologia de Diagnóstico Rápido Participativo (DRP) (BOTELHO; BARTHOLO, 2017), e visitas técnicas de reconhecimento aos empreendimentos identificados no DRP, com a aplicação de questionário para a organização de um inventário ${ }^{[11]}$. A etapa de DRP teve como propósito identificar, de forma participativa e a partir do olhar dos atores locais, os empreendimentos e atrativos turísticos que poderiam compor o roteiro de TBC. Para isso, os atores locais que participaram dos encontros de formação foram convidados a refletir sobre o TBC em Maricá e propor seus próprios roteiros a partir da confecção de mapas ilustrativos confeccionados à mão, destacando-se as particularidades que podem ser experienciadas no município.

A partir dessa etapa metodológica, esses empreendimentos e atrativos foram visitados in loco pela equipe do Projeto de Extensão. Na ocasião das visitas, foram aplicados 21 questionários semiestruturados, elaborados a partir da metodologia de Inventário Turístico do Ministério do Turismo, para o reconhecimento do local pela equipe e o levantamento de dados no âmbito da identificação do empreendimento, do serviço prestado, da forma de organização, dos diferenciais e características da visita. A partir da tabulação dos resultados, um protótipo do roteiro de TBC foi apresentado aos atores locais e gestores públicos para validação, sendo este intitulado "Raízes e Vivências em Maricá". O roteiro foi oficialmente lançado em dezembro de 2017, durante a realização da Feira de Economia Solidária do município. Ao longo do ano de 2018, foram realizadas reuniões 
de acompanhamento do projeto com a prefeitura e empreendimentos do roteiro, além de uma primeira iniciativa de operacionalização com as escolas da rede municipal de ensino.

Com base na breve descrição dos projetos de turismo em curso em Maricá, a seguir é apresentado um quadro analítico dos modelos de desenvolvimento previstos para o município, utilizando como metodologia a análise Swot. É uma ferramenta que serve para o planejamento estratégico de novos projetos, auxiliando na tomada de decisão. Permite a análise de fatores internos (forças e fraquezas) e externos (oportunidades e ameaças) para a compreensão do microambiente e macroambiente (PETROCCHI, 2009).

A seguir é apresentada a análise Swot, de caráter preliminar, para o contexto de Maricá, nos cenários de desenvolvimento do turismo convencional e do turismo de base comunitária (Quadro 1). 
QUADRO 1

Matriz de análise dos modelos de desenvolvimento turístico previstos para Maricá

\begin{tabular}{|c|c|c|}
\hline & Modelo convencional & $\begin{array}{l}\text { Modelo de turismo de base } \\
\text { comunitária } \\
\end{array}$ \\
\hline Forças & $\begin{array}{l}\text { Geografia do município composta } \\
\text { por área balnear; - Areas verdes e } \\
\text { pouco exploradas pela especulação } \\
\text { imobiliária; · Apoio da Companhia } \\
\text { de Desenvolvimento de Maricá } \\
\text { (Codemar); - Interesse por parte da } \\
\text { comunidade na geração de emprego } \\
\text { e renda, e efeito na permanência da } \\
\text { população jovem; - Alternativa } \\
\text { futura de arrecadação municipal } \\
\text { atualmente baseada nos royalties de } \\
\text { petróleo; - Existência de outros } \\
\text { empreendimentos turísticos } \\
\text { estrangeiros; - Ingresso de recursos } \\
\text { privados para o municipio. }\end{array}$ & $\begin{array}{l}\text { - Existência de comunidades } \\
\text { tradicionais; · Organização } \\
\text { comunitária (associações de } \\
\text { moradores, de artesãos e de } \\
\text { agricultores familiares); . Existência } \\
\text { de uma Secretaria de Economia } \\
\text { Solidária atuante desde 2015; } \\
\text { - Recursos públicos municipais } \\
\text { aplicados para o fomento do TBC; } \\
\text { - Fortalecimento do cooperativismo } \\
\text { local; · Existência de produtos locais } \\
\text { (ex.: artesanato, tapeçaria, mel e } \\
\text { cervejas artesanais); Engajamento } \\
\text { de parte dos atores locais; · Criação } \\
\text { do roteiro de TBC "Raízes e } \\
\text { vivências em Maricá" em parceria } \\
\text { entre a Prefeitura, a Unirio e a SRTE- } \\
\text { RJ. }\end{array}$ \\
\hline Fraque zas & $\begin{array}{l}\text { - Geração de conflitos } \\
\text { socioambientais com as } \\
\text { comunidades tradicionais; } \\
\text { - Geração de impactos ambientais } \\
\text { negativos em áreas de unidade de } \\
\text { conservação; . Existência de } \\
\text { espécies endêmicas de fauna e flora } \\
\text { ameaçadas na APA-Maricá; } \\
\text { Aumento da especulação } \\
\text { imobiliária e supervalorização dos } \\
\text { imóveis e de terras. }\end{array}$ & $\begin{array}{l}\text { Conhecimento sobre TBC ainda } \\
\text { pouco difundido entre a gestão } \\
\text { pública e os atores locais; } \\
\text { - Implantação de projetos de } \\
\text { desenvolvimento turístico que não } \\
\text { valorizam as iniciativas locais; } \\
\text {. Necessidade de maiores } \\
\text { investimentos públicos; · Pouca } \\
\text { açấo da Secretaria de Turismo nesta } \\
\text { temática. }\end{array}$ \\
\hline Oportu nidades & $\begin{array}{l}\text { Localização favorável do } \\
\text { municipio em relação à capital do } \\
\text { estado do Rio de Janeiro; - Maior } \\
\text { visibilidade do municipio na mídia } \\
\text { nacional e internacional; } \\
\text { Descentralização da oferta } \\
\text { turistica e dinamização do turismo } \\
\text { no estado do Rio de Janeiro; } \\
\text { Crescimento do interesse privado } \\
\text { na modernização do território local. }\end{array}$ & $\begin{array}{l}\text {. Localização favorável do } \\
\text { município em relação à capital do } \\
\text { estado do Rio de Janeiro; } \\
\text { - Disseminação do modelo de TBC } \\
\text { em âmbito estadual, nacional e } \\
\text { internacional; . Aumento das } \\
\text { experiências de TBC no estado do } \\
\text { Rio de Janeiro; - Identificação do } \\
\text { TBC como alternativa de } \\
\text { conservação dos recursos naturais } \\
\text { pelos órgấos ambientais (ex.: } \\
\text { ICMBio); Aprovação do Projeto de } \\
\text { Lei no 3.598/2017 que institui a } \\
\text { Política Estadual de Turismo } \\
\text { Comunitário no Rio de Janeiro. }\end{array}$ \\
\hline Ameaças & $\begin{array}{l}\text { Crise econômica do estado do Rio } \\
\text { de Janeiro e crescimento do } \\
\text { desemprego; · Proximidade coma } \\
\text { capital pode enfraquecer o interesse } \\
\text { por uma estada prolongada na } \\
\text { cidade; Concorrência com outros } \\
\text { municipios vizinhos e } \\
\text { empreendimentos turísticos já } \\
\text { consolidados no estado. }\end{array}$ & $\begin{array}{l}\text { Crise econômica do estado do Rio } \\
\text { de Janeiro e crescimento do } \\
\text { desemprego; - Concorrência perante } \\
\text { outras iniciativas de TBC mais } \\
\text { antigas e divulgadas no estado. }\end{array}$ \\
\hline
\end{tabular}

Elaboração própria.

A partir da análise anterior, é possível perceber que ambos os modelos podem trazer benefícios e dificuldades ao fortalecimento do turismo como estratégia de desenvolvimento local para Maricá. 
Com relação ao modelo convencional, seu principal expoente é o complexo-turístico São Bento da Lagoa. Este conta com forças internas, como a possibilidade de arrecadação municipal (principalmente quando a exploração do petróleo não se apresentar mais como alternativa econômica), o apoio de parte da população interessada na geração de emprego e permanência dos jovens no município, uma vez que Maricá ainda é conhecida como uma cidade-dormitório. Além disso, a atração de investimentos privados externos é outra possível justificativa para o desenvolvimento do modelo convencional. Vale destacar também que a Codemar, além de apoiar o complexo turístico, vem fomentando outras iniciativas baseadas em um modelo de desenvolvimento que privilegia investimentos externos e a exploração dos recursos naturais, como o projeto do Terminal Petrolífero Ponta Negra, mais conhecido como Porto de Jaconé.

Por outro lado, outras forças internas voltadas ao TBC compreendem o apoio da academia e da Secretaria de Economia Solidária para o seu fortalecimento; a existência de comunidades tradicionais e o interesse da prefeitura em promover o cooperativismo, por meio da realização semanal da Feira de Economia Solidária; da expansão da moeda social Mumbuca; da criação de um banco comunitário; do lançamento do Roteiro Raízes e Vivências em Maricá em parceria com a Unirio, e, mais recentemente, do início do projeto-piloto Mumbuca Futuro, que tem como objetivo introduzir o tema da economia solidária nas escolas municipais e despertar nos jovens um espírito de coletividade e empreendedorismo. Com relação às comunidades tradicionais, Maricá conta com duas aldeias indígenas, diversas associações de artesãos e de agricultores familiares, além de cooperativas e associaçóes de pescadores. Ocorrem, periodicamente, diversas feiras e eventos organizados pela Secretaria de Economia Solidária, com o envolvimento ativo de outros órgãos da prefeitura e dos atores locais.

No que diz respeito às oportunidades externas, o modelo tradicional pode ser favorecido pela crescente visibilidade e interesse privado pelo município de Maricá, com o apoio da própria prefeitura. Além disso, a política de descentralização da oferta turística e de dinamização do turismo no estado do Rio de Janeiro são oportunidades para o município, principalmente levando em consideração sua localização próxima à capital do estado e o crescente interesse privado no território local. Mas o modelo alternativo pode ser impulsionado com a aprovação, em 2017, da Política Estadual de Turismo Comunitário no Rio de Janeiro, de autoria da deputada estadual Rosângela Zeidan, residente em Maricá.

Outra oportunidade é a disseminação das experiências de TBC no estado do Rio de Janeiro e a crescente preocupação com a conservação dos recursos naturais, principalmente com o apoio recente do ICMBio para o fortalecimento de experiências de TBC em unidades de conservação. Entre as iniciativas do ICMBio estão o lançamento do documento “Turismo de Base Comunitária em UCs Federais: princípios e diretrizes” (MMA, 2018), e um edital, lançado em 2017, que tinha por objetivo a seleção de iniciativas e produtos de TBC, com potencial de pautarem métodos passíveis de serem replicados em outras UCs.

Com relação às fraquezas internas que podem prejudicar a implantação do modelo convencional de turismo, destacam-se os conflitos socioambientais com as comunidades tradicionais, como, por exemplo, o que já vem ocorrendo entre grupos de pescadores artesanais e o grupo empresarial IDB Brasil; os impactos ambientais negativos, principalmente na área da restinga de Maricá, que abriga espécies endêmicas de flora e fauna; e o possível aumento da especulação imobiliária. Já as fraquezas do TBC envolvem a necessidade de maior investimento público, do ponto de vista financeiro e de recursos humanos; o desconhecimento de parte da gestão pública e da população local sobre o tema e sobre como implementar empreendimentos econômicos solidários vinculados ao turismo; a concorrência desleal entre os empreendimentos tradicionais e os empreendimentos econômicos solidários; e a pouca atuação da Secretaria de Turismo nas ações que vêm sendo encampadas pela Secretaria de Economia Solidária para o fortalecimento do TBC.

Por fim, as ameaças aos dois modelos contemplam a crise econômica atual pela qual vem passando o estado do Rio de Janeiro (FIRJAN, 2019) e a concorrência entre os municípios e entre as experiências de TBC no estado. Vale destacar que a existência de outras iniciativas de TBC mais antigas e consolidadas podem servir de base para o projeto inicial de TBC em Maricá e, até mesmo, como uma oportunidade, se os municípios e os empreendimentos entenderem que a criação de uma rede entre eles pode beneficiar todos 
nos processos de divulgação, aprendizagem mútua e força na reivindicação de políticas públicas estaduais. Para isso, a competição deve se transformar em cooperação, o que ainda não é possível identificar no estado do Rio de Janeiro.

Vale destacar ainda que a forte atuação da Secretaria de Economia Solidária, no contexto de Maricá, garante ao projeto de TBC uma base ideológica, sob princípios da autogestão, da cooperação, da solidariedade, da repartição de benefícios econômicos e da conservação dos recursos naturais. Um diferencial é que este projeto envolve outras secretarias, mesmo que de forma indireta, tais como: Educação, Meio Ambiente, Agricultura, Comunicação e Cultura. No entanto, entende-se que a atuação da Secretaria de Turismo seria de fundamental importância para garantir a continuidade e a visibilidade das ações.

\section{CONSIDERAÇÕES FINAIS}

Este trabalho teve como objetivo analisar os dois modelos vigentes para o desenvolvimento do turismo em Maricá - o modelo convencional e o TBC. Para tanto, as questões que nortearam esta pesquisa foram: Como a atividade turística pode contribuir para a valorização das iniciativas locais em Maricá? Como conciliar os diferentes interesses envolvidos no planejamento e na gestão do turismo no local estudado?

Diante desses propósitos, a análise realizada, de caráter preliminar, permitiu identificar pontos positivos e negativos de ambos os modelos de turismo no município. Mas, no que diz respeito à valorização das iniciativas locais e à promoção de um desenvolvimento local que contemple a economia, ambiente e sociedade, o modelo do turismo de base comunitária parece ser o mais vantajoso. Contudo, essa possibilidade depende de uma continuidade das ações de TBC por parte da gestão pública e, sobretudo, de uma maior mobilização e organização da sociedade civil por meio de associações de moradores, cooperativas, e grupos informais de produção e comercialização de bens e serviços locais baseados nos princípios da economia solidária.

Em função da existência de diferentes interesses envolvidos no planejamento e na gestão do turismo no local, é importante, também, a coexistência de ambos os modelos analisados. Apesar de divergentes nas suas características e formas de promover o desenvolvimento local, os dois podem trazer benefícios. $\mathrm{O}$ modelo convencional do complexo turístico-residencial, se de fato implementado, garantirá uma série de ganhos econômicos para uma parcela da população, além de maior visibilidade do município, atração de investimentos e a possibilidade de permanência dos residentes no território. Já o modelo alternativo do projeto de TBC, se perpetuado, poderá garantir ganhos econômicos para os pequenos produtores locais, menor impacto ambiental, valorização social e cultural das comunidades e dos modos de vida tradicionais existentes em Maricá, além de promover uma troca de experiências entre visitantes e visitados.

Nesse contexto, Maricá poderá obter ganhos com a coexistência de ambos os projetos apresentados. Mas, para um equilíbrio dessa coexistência é necessário que a gestão pública tenha o mesmo empenho no fomento a esses dois modelos, garantindo a participação dos atores locais nas tomadas de decisões, no monitoramento dos projetos e na devida correção dos impactos negativos, de forma periódica.

Levando em consideração que não existe um padrão predeterminado para o desenvolvimento do turismo, o contexto atual do município de Maricá se mostra favorável à implementação de ações que contemplam os diferentes interesses. Para tanto, algumas recomendações para um adequado desenvolvimento da atividade turística em Maricá devem envolver: valorizar as especificidades locais; garantir a participação ativa da população local nos projetos, independente dos seus modelos; monitorar constantemente os impactos gerados a fim de minimizá-los; preservar as características histórico-culturais e ambientais do município; disseminar os princípios do TBC para todos os gestores públicos; apoiar financeiramente o projeto de TBC, uma vez que a instalação do complexo turístico terá representativo subsídio privado internacional; além de garantir benefícios econômicos para os empreendimentos de pequeno porte que desejam se inserir no turismo. 
As limitações deste estudo compreendem, sobretudo, a análise de dados secundários, o que reduz o entendimento acerca da percepção dos atores locais envolvidos nos processos de desenvolvimento dos dois modelos de turismo em questão. Além disso, a carência de dados sobre os projetos municipais voltados ao turismo é outro fator limitante da análise $S$ wot realizada. Caminhos para futuras pesquisas poderiam envolver um levantamento de dados primários com a prefeitura e atores locais, pesquisas na área ambiental levando em consideração o aumento do número de visitantes nas áreas naturais protegidas inseridas no município, e pesquisas sobre o real impacto econômico dos investimentos público e privado em ambos os modelos de desenvolvimento.

\section{REFERÊNCIAS}

ANTUNES, D. C.; CONTI, B. R. Dilemas de uma Nova Agenda de Desenvolvimento: um olhar sobre a Política Ambiental Brasileira. Desenvolvimento e Meio Ambiente. Editora UFPR, n. 25, p. 73-86, 2012.

BOTELHO, E. S.; BARTHOLO, R. Desenvolvimento Local e o Turismo em Parques Nacionais: os casos da Restinga de Jurubatiba e do Quilombo Machadinha. In: XIV SEMINÁRIO DA ANPTUR. 13 a 15 de setembro de 2017. Anais... Balneário Camboriú: Universidade do Vale do Itajaí, 2017.

BRASIL. Ministério do Meio Ambiente. Turismo de Base Comunitária em Unidades de Conservação Federais: princípios e diretrizes. Disponível em: . Acesso em: 27 fev. 2019.

BURGOS, A.; MERTENS, F. Os desafios do turismo no contexto da sustentabilidade: as contribuições do turismo de base comunitária. PASOS. Revista de Turismo y Patrimonio Cultural. Ilhas Canárias, Espanha, v. 13, n. 1, p. 57-71, 2015.

BURSZTYN, I.; BARTHOLO, R. O processo de comercialização do turismo de base comunitária no Brasil: desafios, potencialidades e perspectivas. Sustentabilidade em Debate. Brasília, v. 3, n. 1, p. 97-115, 2012.

CALEGARE, M.; SILVA JÚNIOR, N. da. Progresso, desenvolvimento sustentável e abordagens diversas de desenvolvimento: uma sucinta revisão de literatura. Desenvolvimento e Meio Ambiente. Curitiba, n. 24, p. 39-76, jul./dez. 2011.

COMISSÃO MUNDIAL DO MEIO AMBIENTE E DESENVOLVIMENTO. Nosso futuro comum. 2. ed. Tradução de Our common future. 1988. Rio de Janeiro: Editora da Fundação Getúlio Vargas, 1991.

CONTI, B. R.; ROCHA, L. R. V. G.; VITEZE, N. N. As conexões entre a economia solidária e o turismo de base comunitária no estado do Rio de Janeiro. Revista Acadêmica Observatório de Inovação do Turismo. Rio de Janeiro, v. 12, n. 2, p. 1-21, dez. 2018.

CORIOLANO, L. N. A contribuição do turismo ao desenvolvimento local. In: PORTUGUEZ, A. P.; SEABRA, G. de F.; QUEIROZ, O. T. M. M. Turismo, espaço e estratégias de desenvolvimento local. João Pessoa: Editora Universitária da UFPB, p. 61-70, 2012.

FABRINO, N. H.; NASCIMENTO, E. P. do; COSTA, H. A. Turismo de Base Comunitária: uma reflexão sobre seus conceitos e práticas. Caderno Virtual de Turismo. Rio de Janeiro, v. 16, n. 3, p. 172-190, dez. 2016.

FEDERAÇÃO DAS INDÚSTRIAS DO ESTADO DO RIO DE JANEIRO. Índice Firjan de Desenvolvimento Municipal 2018. Disponível em: . Acesso em: 27 fev. 2019.

GABRIELLI, C. P. Turismo responsável: caminhos possíveis? Revista de Turismo Contemporâneo. Natal, v. 5, n. 1, p. 81-97, jan./jun. 2017.

GÓMEZ, C. R. P. et al. Turismo de Base Comunitária como Inovação Social: congruência entre os constructos. PASOS. Revista de Turismo y Patrimonio Cultural. Ilhas Canárias, Espanha, v. 13, n. 5, p. 1213-1227, 2015.

HALL, C. M. Política e planejamento turístico: o imperativo sustentável. In: políticas, processos e relacionamentos. São Paulo: Contexto, 2001. p. 17-36. . Planejamento turístico:

IRVING, M. A. Reinventando a reflexão sobre turismo de base comunitária: inovar é possível? In: BARTHOLO, R.; SANSOLO, D. G.; BURSZTYN, I. (Org.). Turismo de base comunitária: diversidade de olhares e experiências brasileiras. Rio de Janeiro: Letra e Imagem, 2009. 
KRIPEENDORF, J. Sociologia do turismo: para uma nova compreensão do lazer e das viagens. São Paulo: Aleph, 2000.

LOUREIRO, D. S.; MATIAS, M. L.; FREIRE, D. G. Avaliação do conflito socioambiental na APA da restinga de Maricá - RJ. XVI Encontro Nacional dos Geógrafos. Porto Alegre, p. 10, 2010.

MATIAS, M. L.; CORREA, G. S. "R" de restinga ou de resort? O novo arranjo no setor imobiliário-turístico em Maricá, no contexto do Leste Metropolitano do Rio de Janeiro. XVI ENCONTRO NACIONAL DOS GEÓGRAFOS. 25 a 31 de julho de 2010. Porto Alegre. Anais... Crise, práxis e autonomia: espaços de resistência e de esperanças. Espaço de Diálogos e Práticas. Porto Alegre, RS, 2010.

MENDONÇA, T. C. M.; MORAES, E. A.; CATARCIONE, F. L. C. Turismo de Base Comunitária na região da Costa Verde (Rio de Janeiro): refletindo sobre um turismo que se tem e um turismo que se quer. Caderno Virtual de Turismo. Rio de Janeiro, v. 16, n. 2, p. 232-248, 2016.

MIELKE, E. J. C. Monitoramento dos Projetos de Turismo de Base Comunitária: relatório final. Rio de Janeiro: Universidade do Estado do Rio de Janeiro, 2011.

MIELKE, E. J. C.; PEGAS, F. V. Turismo de Base Comunitária. Insustentabilidade é uma questão de gestão. Revista Turismo em Análise. São Paulo, v. 24, n. 1, 170-189, 2013.

OKAZAKI, E. A Community-Based Tourism Model: its conception and use. Journal of Sustainable Tourism, v. 16, n. 5, p. 511-529, 2008.

PEREIRA, M. C. B.; MELLO, Y. R. Projetos globais e resistências locais: pescadores artesanais e Unidades de Conservação no litoral, Rio de Janeiro - Brasil. Desenvolvimento e Meio Ambiente. Curitiba, n. 24, p. 137-150, 2011.

PETROCCHI, M. Turismo: planejamento e gestão. São Paulo: Pearson Prentice Hall, 2009.

SACHS, I. Stratégies de I'écodéveloppement. Paris: Lês Editions Ouvrières, 1980.

SEN, A. Desenvolvimento como liberdade. São Paulo: Companhia das Letras, 2000.

SILVA, M. D. G.; MIRANDA, E de A. Planejamento do turismo para o desenvolvimento local. Revista Brasileira de Planejamento e Desenvolvimento. Curitiba, v. 2, n. 2, p. 94-103, jul./dez, 2013.

SILVA, T. do N. et al. Turismo de base comunitária: o agente indutor e as experiências do Ministério do Turismo (edital 001/2008). ENCONTRO INTERNACIONAL SOBRE GESTÃO EMPRESARIAL E MEIO AMBIENTE, 2016.

SOUZA, E. M. S. Um resort na restinga de Maricá/RJ: modernização do território e destruição da pesca artesanal em uma área de proteção ambiental. Espaço e Economia. Rio de Janeiro, n. 6, 2015.

STIGLITZ, J. A globalização e seus malefícios: a promessa não cumprida de benefícios globais. São Paulo: Futura, 2002.

TURISOL. Histórico. Disponível em: . Acesso em: 27 fev. 2019.

VEAL, A. J. Metodologia de pesquisa em lazer e turismo. São Paulo: Aleph, 2011.

YÁZIGI, E. Saudades do futuro: por uma teoria do planejamento territorial do turismo. São Paulo: Plêiade, 2009.

YIN, R. K. Estudo de Caso, planejamento e métodos. 2. ed. São Paulo: Bookman, 2001.

\section{NOTAS}

[1] A autora diferencia o turismo tradicional do turismo alternativo como sendo "resultantes de apreciações práticas das mudanças ocorridas nas sociedades" e cita o TBC como uma forma de turismo alternativo (GABRIELLI, 2017, p. 88).

[2] Para uma revisão sobre as novas concepções de desenvolvimento, tendo em vista o contexto do desenvolvimento sustentável, consultar Calegare e Silva Júnior (2011).

[3]Informação disponível em: https://maricainfo.com/2017/05/01/marica-e-o-municipio-que-recebeu-mais-verbas-dosroyalties-de-petroleo-em-2017.html Acesso em: 20 out. 2017. 
[4] A Área de Proteção Ambiental de Maricá foi criada pelo Decreto no 7.230, de 23 de abril de 1984, mas apenas em 2007 foi decretado seu Plano de Manejo. Disponível em: http://www.mma.gov.br/port/conama/processos/AD9BCD27/ Compara_Decreto41048_DeliberaCECA.pdf Acesso em: 09 dez. 2017.

[5] Em ecologia, o termo restinga é utilizado para definir diferentes formações vegetais que se estabelecem sobre solos arenosos na região da planície costeira. Esses ecossistemas são determinados fisicamente pelas condições edáficas (solo arenoso) e pela influência do mar, e estão distribuídos ao longo do litoral brasileiro. Disponível em: http://www.zonacosteira.bio.ufba.br/vrestinga.html . Acesso em: 20 out. 2017.

[6] Entrevista realizada no âmbito do Projeto de Extensão "Economia Solidária e Turismo de Base Comunitária em Maricá, RJ” durante a etapa de inventário dos empreendimentos de TBC.

[7] Idem.

[8]Disponível em: http://200.20.53.3:8081/cs/groups/public/documents/document/zwew/mdm2/ edisp/inea0036127.pdf. Acesso em: 09 dez. 2017.

[8]Disponível em: http://agenciabrasil.ebc.com.br/geral/noticia/2016-04/alerj-denuncia-ameaca-pescadores-e-ambiente-porcomplexo-turistico-em-maricaa Acesso em: 09 dez. 2017.

[9]Disponível em: http://agenciabrasil.ebc.com.br/geral/noticia/2016-04/alerj-denuncia-ameaca-pescadores-e-ambiente-porcomplexo-turistico-em-maricaa. Acesso em: 09 dez. 2017.

[10] A moeda social "Mumbuca" é um programa de distribuição de renda da Prefeitura de Maricá (Lei no 2.448 , de 26 de junho de 2013, que institui o Programa Municipal de Economia Solidária, Combate à Pobreza e Desenvolvimento Econômico e Social de Maricá). Disponível em: http://www.institutobancopalmas.org/cgi-sys/suspendedpage.cg. . Acesso em: 15 out. 2017.

[11] O inventário utilizado foi construído com base na metodologia do Ministério do Turismo e adaptado para o contexto do projeto de extensão e do município de Maricá.

\section{BY}

